\title{
Prognostications With Applications to the British Pound
}

\author{
Augustine C. Arize ${ }^{1}$, John Malindretos ${ }^{2}$, Tao Guo ${ }^{3}$, Demetri Tsanacas ${ }^{2} \&$ Lawrence Verzani $^{2}$ \\ ${ }^{1}$ Department of Economics and Finance, College of Business, Texas A\&M University, College Station, Texas, USA \\ ${ }^{2}$ Department of Economics, Finance and Global Business, Cotsakos College of Business, William Paterson \\ University, Wayne, New Jersey, USA \\ ${ }^{3}$ Department of Economics, Finance and Global Business, William Paterson University, Wayne New Jersey, USA \\ Correspondence: John Malindretos, Department of Economics, Finance and Global Business, Cotsakos College of \\ Business, William Paterson University, Wayne, New Jersey, USA.
}

Received: November 21, 2018

Accepted: May 23, 2019

Online Published: July 22, 2019

doi:10.5430/ijfr.v10n4p143

URL: https://doi.org/10.5430/ijfr.v10n4p143

\begin{abstract}
This paper scrutinizes several exchange rate models, considers the effectiveness of their predictive performance after applying both parametric and nonparametric techniques to them, and chooses the forecasting predictor with the smallest root mean square forecast error (RMSE). Equation (34) displays empirical evidence consistent with a better example of an exchange rate model, although none of the evidence gives us a completely satisfactory forecast. In the end, the models' error correction versions will be fit so that plausible long-run elasticities can be imposed on each model's fundamental variables.
\end{abstract}

Keywords: efficiency, exchange rate determination, exchange rate policy, forecasting, foreign exchange

\section{Introduction}

Most economic time series do not have an invariant mean because they alternate phases of relative stability with periods of greater volatility. For example, an initial review of time-series data, including but not limited to currency exchange rates implies that these data are heteroscedastic because of the absence of this constant mean and variance, as opposed to being homoscedastic because of the presence of a stochastic variable with a constant variance. For any series with such volatility, the unconditional variance could be constant even though it could also be unexpectedly large. Some variables' trends can possess stochastic or deterministic characteristics, with the type of estimation and forecast done on these ingredients (namely, a deterministic or a stochastic trend) having a great deal of influence on the results of that time series.

One may illustrate multiple exchange rates' behavior by graphing them, noting their fluctuations across time, and confirming any initial impressions through rigorous testing. For example, these series are not stationary because the sample means have a strong appearance of heteroscedasticity and do not appear to be constant. The absence of any specific trend in these series makes it difficult to prove the existence of a time-invariant mean, with the American dollar-to-British pound exchange rate not showing a tendency of either increasing or decreasing being but one example. The dollar had gone through long periods of appreciation followed by bouts of depreciation without reversion to the long-run average; this sort of "random walk" is quite representative of non-stationary time series.

Any shock to such a series shows great persistence, e.g., the dollar/pound exchange rate experienced a very sharp surge upward in 1980, remained at that level for about four years, and did not return to somewhat near its previous level for another five years. These series' volatility is not constant and some of them correlate with other series. In fact, such series are called "conditionally heteroscedastic" if the unconditional (long-run) variance is constant but also having localized periods of relatively high variance. For instance, large shocks in the U.S. appear nearly simultaneously in Great Britain and Canada, although these co-movements can often be predicted because of the underlying forces affecting all nations' economies, including that of the U.S.

The disturbance term's variance is assumed to be constant in conventional econometric models, although the series alternates unusually volatile periods with spells of relative tranquility. Therefore, the assumption of a constant variance in such unconventional cases is incorrect. As an investor holding only one currency, however, one might wish to forecast both the exchange rate and its conditional variance over the life of the investment. The unconditional 
variance - namely, its long-run forecast - would not be important were one to buy the asset at time period t and sell it at $\mathrm{t}+1$. Taylor (1995) and Kallianiotis (1985) provide a survey and reviews of the literature on exchange rate economics and Chinn and Meese (1995) examine four structural exchange rate models' performance.

This paper is set forth as follows. Different trend models are described in section 2. Other linear time-series models are presented in section 3 with multiequation time-series models defined in section 4 . The empirical results are given in section 5 , with a summary of the findings presented at the end of section 6 .

\section{Time-Series Trends}

One way to predict a time series' variance is to introduce an independent variable that explicitly helps forecast that series' volatility. Consider the simplest case, for example, in which

$$
\mathrm{s} \_(\mathrm{t}+1)=\left(\varepsilon \_(\mathrm{t}+1) \mathrm{X}\right) \_\mathrm{t}
$$

Where s_ $(\mathrm{t}+1)=$ the spot exchange rate or the variable of interest, $\varepsilon_{-}(\mathrm{t}+1)=$ a white-noise disturbance term withvariance $\sigma^{\wedge} 2$, and $X_{-} t=$ an independent variable that can be observed at time period $t$. If $X_{-} \_t=X_{-}(t-1)=X_{-}(t-2)$ $=\ldots=\mathrm{a}$ constant, then the $\left\{\mathrm{s} \_\mathrm{t}\right\}$ sequence is a standard white-noise process with a constant variance.

If the realizations of the $\left\{\mathrm{X}_{-} \mathrm{t}\right\}$ sequence are not all equal, then the variance of $\mathrm{s}_{-}(\mathrm{t}-1)$ that is conditionalon the observable value of $\mathrm{X} \_\mathrm{t}$ is

$$
\operatorname{Var}\left(\mathrm{s} \_(\mathrm{t}+1)(\mathrm{X}) \_\mathrm{t}\right)=\mathrm{X} \mathrm{t}^{\wedge} 2 \sigma^{\wedge} 2
$$

We can represent the general solution to a linear stochastic difference equation with these four components: $s_{-} \mathrm{t}=$ cyclical + irregular + seasonal + trend

Exchange rate series do not have an obvious tendency to revert to any long-run mean. One goal of econometricians is forming well-defined stochastic difference equation models that can simulate trending variables' behavior, with the trends noted for their permanent effects on time series. Because of the stationary nature of the irregular component of a series, its effects will diminish over time while the trending elements and their effects will persist in long-term forecasts.

\subsection{Deterministic Trends}

One of s_t's basic characteristics, despite its short-term volatility, is its long-term growth pattern. In fact, s_t may have a well-defined long-term trend after all. According to the research of Pindyck and Rubinfeld (1981), Chatfield (1985), and Enders (1995), there are at least eight models that both define this deterministic trend and can be used in the extrapolation and forecasting of s_t, and they are:

Linear time trend:

$$
\mathrm{S} \_\mathrm{t}=\alpha \_0+\alpha \_1 \mathrm{t}+\varepsilon_{-} \mathrm{t}
$$

Exponential growth curve:

$$
\mathrm{S} \_\mathrm{t}=A \mathrm{e}^{\wedge} \mathrm{rt}
$$

Or

$$
\ln \mathrm{S} \_t_{-}=\ln \mathrm{A}+\mathrm{rt}+\varepsilon_{-} \mathrm{t}
$$

Or

$$
\mathrm{s}_{-} \mathrm{t}=\beta_{-} 0+\beta \_1 \mathrm{t}+\varepsilon_{-} \mathrm{t}
$$

Logarithmic or stochastic autoregressive trend (the only function that can be applied for exchange rates):

$$
\mathrm{s} \__{-} \mathrm{t}=\gamma_{-} 0+\gamma_{-} 1 \mathrm{~s}_{-}(\mathrm{t}-1)+\varepsilon_{-} \mathrm{t}
$$

Quadratic trend:

$$
\mathrm{s} \_\mathrm{t}=\delta \_0+\delta \_1 \mathrm{t}+\delta_{-} 2 \mathrm{t}^{\wedge} 2+\varepsilon \_\mathrm{t}
$$

Polynomial time trend:

$$
\mathrm{s} \_\mathrm{t}=\zeta \zeta_{-} 0+\zeta_{-} 1 \mathrm{t}+\zeta_{-} 2 \mathrm{t}^{\wedge} 2+\ldots+\zeta \mathrm{nt}^{\wedge} \mathrm{n}+\varepsilon_{-} \mathrm{t}
$$

Logarithmic growth curve:

$$
\mathrm{s} \_\mathrm{t}=1 /\left(\theta \_0+\theta \_1 \quad \theta \_2 \wedge \mathrm{t}\right) ; \theta \_2>0
$$


Or its stochastic approximation:

$$
\left(\Delta \mathrm{s}_{-} \mathrm{t} / \mathrm{s} \_(\mathrm{t}-1)\right)=\mathrm{k}_{-} 0-\mathrm{k}_{-} 1 \mathrm{~s} \_(\mathrm{t}-1)+\varepsilon_{-} \mathrm{t}
$$

Sales saturation pattern:

$$
\mathrm{S} \_\mathrm{t}=\mathrm{e}^{\wedge}\left(\lambda \_0-\left(\lambda \_1 / \mathrm{t}\right)\right)
$$

Or

$$
\mathrm{s} \_\mathrm{t}=\lambda \_0-\left(\lambda \_1 / \mathrm{t}\right)+\varepsilon \_\mathrm{t}
$$

Where $S \_t=$ the spot exchange rate, $t=$ the time trend, and the lowercase letters are the natural logarithms of their uppercase counterparts.

\subsection{Models of Stochastic Trend}

One can increase the deterministic trend models with the lagged values of both the $\left\{s_{-} t\right\}$ and $\left\{\varepsilon_{-} t\right\}$ sequences. These equations thus become models with their own stochastic trends. These models are:

(i) The Random Walk Model

The random walk model, which is actually a special case of the AR(1) process, appears to mimic the exchange rates' behavior as shown below. These time series neither revert to any given mean nor fluctuate over time.

$$
\mathrm{s} \_\mathrm{t}=\alpha \_0+\alpha \_1 \mathrm{~s} \_(\mathrm{t}-1)+\varepsilon \_\mathrm{t}
$$

with $\alpha \_0=0$ and $\alpha \_1=1$, and where $s_{-} t-s_{-}(t-1)=\Delta s_{-} t=\varepsilon \_t$, becomes

$$
\mathrm{s} \_\mathrm{t}=\mathrm{s} \_(\mathrm{t}-1)+\varepsilon \_\mathrm{t}
$$

The conditional mean of $s_{-}(t+\lambda)$ for any $\lambda>0$ is

$$
\text { E_t S_ }(\mathrm{t}+\lambda)=\mathrm{S} \_\mathrm{t}+\mathrm{E} \sum(\mathrm{i}=1)^{\wedge} \lambda \mathrm{i}_{\mathrm{W}} \varepsilon_{-}(\mathrm{t}+\mathrm{i})=\mathrm{s} \_\mathrm{t}
$$

with a time-dependent variance:

$$
\operatorname{var}\left(s_{-} \mathrm{t}\right)=\operatorname{var}\left(\varepsilon_{-} \mathrm{t}+\varepsilon_{-}(\mathrm{t}-1)+\ldots+\varepsilon_{-} 1\right)=\mathrm{t} \sigma^{\wedge} 2
$$

The random walk process is nonstationary because the variance is not constant. Therefore, as

$$
\mathrm{t} \rightarrow \infty \text { and } \operatorname{var}\left(\mathrm{s} \_\mathrm{t}\right) \rightarrow \infty,
$$

the forecast function will be:

(ii) The Random Walk Plus Drift Model

$$
\text { E_t } s_{-}(t+\lambda)=s \_t
$$

The random walk plus drift model adds a constant term $\alpha \_0$ to the random walk model above such that s_t becomes deterministic in part and stochastic in part:

$$
\mathrm{s} \_\mathrm{t}=\mathrm{s} \_(\mathrm{t}-1)+\alpha \_0+\varepsilon \_\mathrm{t}
$$

The general solution for $\mathrm{s} \_t_{\mathrm{t}}$ is:

$$
\mathrm{s} \_\mathrm{t}=\mathrm{s}_{-} 0+\alpha \_0 \mathrm{t}+\sum_{-}(\mathrm{i}=1)^{\wedge} \mathrm{E}
$$

and

$$
\text { E_t } s_{-}(t+\lambda)=s \_0+\alpha \_0(t+\lambda)
$$

The forecast function by $\lambda$ periods yields:

$$
\text { E_t } s_{-}(t+\lambda)=s \_t+\alpha \_0 \lambda
$$

(iii) The Random Walk Plus Noise Model

The $\mathrm{s}_{-} \mathrm{t}$ is obtained here by adding a white-noise component to a stochastic trend:

$$
\mathrm{s} \_\mathrm{t}=\mu \_\mathrm{t}+\mathrm{n} \_\mathrm{t}
$$

and

$$
\mu_{-} \mathrm{t}=\mu_{-}(\mathrm{t}-1)+\varepsilon_{-} \mathrm{t}
$$

Where $\left\{n_{-} t\right\}$ is a white-noise process with variance $\sigma_{-} \mathrm{n}^{\wedge} 2$ and $\varepsilon_{-} \mathrm{t}$ and $\mathrm{n} \_\mathrm{t}_{-} \mathrm{are}$ both independently distributed for all $\mathrm{t}$. $\mathrm{E}\left(\varepsilon_{-} \mathrm{t} \mathrm{n}_{-}(\mathrm{t}-\lambda)\right)=0$ and the $\left\{\mu_{-} \mathrm{t}\right\}$ sequence represents the stochastic trend. This model's solution can be written:

$$
\mathrm{s} \_\mathrm{t}=\mathrm{s} \_0-\mathrm{n} \_0+\sum(\mathrm{i}=1)^{\wedge} \mathrm{t}
$$


The forecast function is:

$$
\text { E_t S_ }(t+\lambda)=s \_t-n \_t
$$

(iv) The General Trend Plus Irregular Model

One can substitute the so-called "trend plus noise model" for equation (25) above:

$$
\mu \_\mathrm{t}=\mu \_(\mathrm{t}-1)+\alpha \_0+\varepsilon \_\mathrm{t}
$$

where $\alpha_{-} 0$ is a constant and $\left\{\varepsilon_{-} t\right\}$ is a white-noise process.

The solution is:

$$
\mathrm{s} \_\mathrm{t}=\mathrm{s} \_0-\mathrm{n} \_0+\alpha \_0 \mathrm{t}+\sum \_(\mathrm{i}=1)^{\wedge} \mathrm{t}
$$

Let $\mathrm{A}(\mathrm{L})$ be a polynomial in the lag operator $\mathrm{L}$. It is possible to supplement a random walk plus drift process with the stationary noise process $\mathrm{A}(\mathrm{L}) \mathrm{n} \mathrm{t}$ and thus obtain the "general trend plus irregular model":

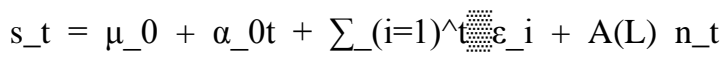

(v) The Local Linear Trend Model

The local linear trend model is constructed by combining several random walk plus noise processes. Let $\left\{\epsilon_{-} t\right\},\left\{n_{-} t\right\}$, and $\left\{\mathrm{u}_{-} \mathrm{t}\right\}$ be three mutually uncorrelated white-noise processes. The equations for the local linear trend model are:

$$
\begin{gathered}
s \_t=\mu \_t+n \_t \\
\mu \_t=\mu \_(t-1)+\alpha \_t+\varepsilon \_t \\
\alpha \_t=\alpha \_(t-1)+u_{-} t
\end{gathered}
$$

This is the most detailed of all the above models because the other processes are special cases of the local linear trend model, which consists of the noise term $n \_t$ and the stochastic trend term $\mu \_t$. What is most important about the model for this paper is that the change in its trend yields a random walk plus noise:

$$
\Delta \mu \_\mathrm{t}=\mu \_\mathrm{t}-\mu \_(\mathrm{t}-1)=\alpha \_\mathrm{t}+\varepsilon_{-} \mathrm{t}
$$

The forecast function of $s_{-}(\mathrm{t}+\lambda)$ equals the current value of $s_{-} t$ minus the transitory component $n \_t$, added to $\lambda$ multiplied by the slope of the trend term in $\mathrm{t}$ :

$$
\text { E_t } \mathrm{s}_{-}(\mathrm{t}+\lambda)=\left(\mathrm{s} \_\mathrm{t}-\mathrm{n} \_\mathrm{t}\right)+\lambda\left(\alpha_{-} 0+\mathrm{u} \_1+\mathrm{u} \_2+\ldots+\mathrm{u} \_\mathrm{t}\right)
$$

In the future, one may estimate these models and run different tests on both the error terms and the series as well as conclude with diagnostic and specification tests as a way of gauging the statistical specifications' fitness and then compare the forecasting results obtained from the different models.

\section{Some Linear Time-Series Models}

In this section, stochastic processes are defined and some of their properties are discussed for use in forecasting, with a view toward developing models that explicate the movement of the time series s_t. However, this will not be accomplished using explanatory variables per the regression model but by relating the series to its previous values and to a weighted sum of lagged and current random disturbances.

\subsection{The Autoregressive (AR) Model}

In the autoregressive process of order $\mathrm{p}$, the current observation s_t is generated by a weighted average of past observations going back $\mathrm{p}$ time periods, together with the current time period t's random disturbance. This process is defined as $\operatorname{AR}(p)$ and is written:

$$
\mathrm{s} \_\mathrm{t}=\phi \_1 \text { s_(t-1) }+\phi \_2 \mathrm{~s} \_(\mathrm{t}-2)+\ldots+\phi \_\mathrm{p} s \_(\mathrm{t}-\mathrm{p})+\delta+\varepsilon \_\mathrm{t}
$$

$\delta$ is a constant term which relates to the mean, or arithmetic average, of the stochastic process.

The first-order process $\operatorname{AR}(1)$ is:

$$
\mathrm{s} \_\mathrm{t}=\phi_{-} 1 \mathrm{~s} \_(\mathrm{t}-1)+\delta+\varepsilon \_\mathrm{t}
$$

and its mean is:

$$
\mu=\delta /\left(1-\phi \_1\right)
$$

and is also stationary if $\phi_{-} 1<1$. (The random walk with drift is a first-order autoregressive process that is not stationary, however.) 


\section{Empirical Evidence}

An analysis and summary of the empirical evidence for different models of foreign currency forecasting is included.The data given below are monthly from March 1973 through and including December 1994, are coming from Main Economic Indicators of the OECD (the Organization for Economic Cooperation and Development) and International Financial Statistics of the IMF (the International Monetary Fund), and they have been applied for the United Kingdom (U.K.). The exchange rate is defined as the U.S. dollar per unit of the British pound, with direct quotes for the dollar; the lowercase letters denote the variables' natural logarithms and an asterisk denotes the corresponding variable for the U.K.

The first equations estimated are the deterministic trend models in equations (3), (6), (8), (9), (11), and (13). The results appear in Table 1 below and indicate that the exchange rate forecast cannot be supported by models of this type. The second group of equations, encompassing (15) and (20) in Table 2, is for the stochastic trend model and shows that this alternative model is noticeably better at both interpreting the data and forecasting the exchange rate. The final model is of a linear time-series, namely, the autoregressive (AR) model of equation (34) shown in Table 3, but its results are also mediocre at best. One may infer that time-series models cannot be used in the forecasting of foreign currency exchange rates with a great degree of confidence for models with such relatively high volatility.

Table 1. Deterministic trends

\begin{tabular}{|c|c|c|c|}
\hline \multicolumn{2}{|c|}{$\begin{array}{l}\text { (i) Linear time trend, eq. (3): } \\
S_{t}=\alpha_{0}+\alpha_{1} t+\varepsilon_{t}\end{array}$} & \multicolumn{2}{|c|}{$\begin{array}{l}\text { (ii) Exponential Growth Curve, eq. (6): } \\
s_{t}=\beta_{0}+\beta_{1} t+\varepsilon_{t}\end{array}$} \\
\hline$\alpha_{0}$ & $223.426^{* * *}$ & $\beta_{0}$ & $5.405^{* * *}$ \\
\hline & $(3.750)$ & & $(.021)$ \\
\hline$\alpha_{1}$ & $-.277^{* * *}$ & $\beta_{1}$ & $-.001^{* * *}$ \\
\hline & $(.022)$ & & $(.0001)$ \\
\hline$R^{2}$ & .385 & $R^{2}$ & .353 \\
\hline $\mathrm{D}-\mathrm{W}$ & .053 & $\mathrm{D}-\mathrm{W}$ & .053 \\
\hline SSR & $172,066.8$ & SSR & 5.446 \\
\hline $\mathrm{F}$ & 158.920 & $\mathrm{~F}$ & 138.75 \\
\hline RMSE & 25.9256 & RMSE & .1458 \\
\hline \multicolumn{2}{|c|}{ (iii) Quadratic Trend, eq. (8): } & \multicolumn{2}{|c|}{ (iv) Polynomial time trend, eq. (9): } \\
\hline \multicolumn{2}{|c|}{$s_{t}:=\delta_{0}+\delta_{1} t+\delta_{2} t^{2}+\varepsilon_{t}$} & \multicolumn{2}{|c|}{$s_{t}=\zeta_{0}+\zeta_{1} t+\zeta_{2} t^{2}+\ldots+\zeta_{n} t^{n}+\varepsilon_{t}$} \\
\hline \multirow[t]{2}{*}{$\delta_{0}$} & $5.633^{* * *}$ & $\zeta_{0}$ & $3.621^{* * *}$ \\
\hline & $(.036)$ & & $(.487)$ \\
\hline \multirow[t]{2}{*}{$\delta_{1}$} & $-.005^{* * *}$ & $\zeta_{1}$ & $.189^{* * *}$ \\
\hline & $(.0005)$ & & $(.035)$ \\
\hline \multirow[t]{10}{*}{$\delta_{2}$} & $1.0-05^{* * *}$ & $\zeta_{2}$ & $-.007^{* * *}$ \\
\hline & $(2.0-06)$ & & $(.001)$ \\
\hline & & $\zeta_{3}$ & $.0001^{* * *}$ \\
\hline & & & $(1.4-05)$ \\
\hline & & $\zeta_{4}$ & $-9.9-07^{* * *}$ \\
\hline & & & $(1.1-07)$ \\
\hline & & $\zeta_{5}$ & $4.7-09^{* * *}$ \\
\hline & & & $(4.7-10)$ \\
\hline & & $\zeta_{6}$ & $-1.1-11^{* * *}$ \\
\hline & & & $(1.1-12)$ \\
\hline
\end{tabular}




\begin{tabular}{|c|c|c|c|}
\hline \multirow[b]{2}{*}{$R^{2}$} & \multirow[b]{2}{*}{.468} & $\zeta_{7}$ & \multirow{2}{*}{$\begin{array}{l}1.1-14^{* * *} \\
(9.9-16) \\
.780\end{array}$} \\
\hline & & $R^{2}$ & \\
\hline D-W & .065 & D-W & .152 \\
\hline SSR & 4.478 & SSR & 1.850 \\
\hline$F$ & 111.35 & $\mathrm{~F}$ & 125.84 \\
\hline RMSE & .1323 & RMSE & .0850 \\
\hline \multicolumn{2}{|c|}{$\begin{array}{l}\text { (v) Stochastic approximation, eq. (11): } \\
\left(\Delta s_{t} / s_{t-1}\right)=k_{0}-k_{1} s_{t-1}+\varepsilon_{t}\end{array}$} & \multicolumn{2}{|c|}{$\begin{array}{l}\text { (vi) Sales Saturation Pattern, eq. (13): } \\
s_{t}=\lambda_{0}-\left(\lambda_{1} / t\right)+\varepsilon_{t}\end{array}$} \\
\hline \multirow[t]{2}{*}{$k_{0}$} & $.114^{*}$ & $\lambda_{0}$ & $5.025^{* * *}$ \\
\hline & $(.060)$ & & $(.014)$ \\
\hline \multirow[t]{2}{*}{$k_{1}$} & $-.022^{*}$ & $\lambda_{1}$ & $16.668^{* * *}$ \\
\hline & $(.011)$ & & (1.196) \\
\hline$R^{2}$ & .015 & $R^{2}$ & .433 \\
\hline D-W & 1.772 & D-W & .061 \\
\hline SSR & .285 & SSR & 4.772 \\
\hline $\mathrm{F}$ & 3.796 & $\mathrm{~F}$ & 194.20 \\
\hline RMSE & .0333 & RMSE & .1365 \\
\hline
\end{tabular}

Notes: $S_{t}=$ the spot exchange rate, $s_{t}=\ln \left(S_{t}\right), \mathrm{t}=$ time, $\mathrm{D}-\mathrm{W}=$ the Durbin-Watson statistic, SSR $=$ sum of squares residuals, RMSE = root mean square error, data from 1973.03 to $1994.06, * * *=$ significant at the $1 \%$ level, $* *=$ significant at the $5 \%$ level, $*=$ significant at the $10 \%$ level, $\Delta=$ change of the variable.

Table 2. Stochastic trends

\begin{tabular}{|c|c|c|c|}
\hline \multicolumn{2}{|c|}{$\begin{array}{l}\text { (i) The Random Walk Model, eq. (15): } \\
s_{t}=s_{t-1}+\varepsilon_{t}\end{array}$} & \multicolumn{2}{|c|}{$\begin{array}{l}\text { (ii) The Random Walk plus Drift Model, eq. (20): } \\
s_{t}=\alpha_{1} s_{t-1}+\alpha_{0}+\varepsilon_{t}\end{array}$} \\
\hline \multirow[t]{4}{*}{$s_{t-1}$} & $1.000^{* * *}$ & $\alpha_{0}$ & $.114^{*}$ \\
\hline & $(.0004)$ & & $(.060)$ \\
\hline & & $\alpha_{1}$ & $.978^{* * *}$ \\
\hline & & & $(.011)$ \\
\hline$R^{2}$ & .966 & $R^{2}$ & .966 \\
\hline D-W & 1.785 & $\mathrm{D}-\mathrm{W}$ & 1.772 \\
\hline $\begin{array}{l}\text { SSR } \\
\end{array}$ & .289 & SSR & .285 \\
\hline $\mathrm{L}()$. & 505.31 & $\bar{F}$ & $7,246.64$ \\
\hline RMSF & .0336 & RMSE & .0334 \\
\hline
\end{tabular}

Notes: See the previous table. L(.) = logarithm of likelihood function.

Table 3. Linear time-series models

\begin{tabular}{cc}
\hline The Autoregressive (AR) Model, eq. (34): $s_{t}=\phi_{1} s_{t-1}+\phi_{2} s_{t-2}+\ldots+\phi_{p} s_{t-p}+\delta+\varepsilon_{t}$ \\
\hline$\delta$ & $5.139^{* * *}$ \\
& $(.078)$ \\
\hline$\phi_{1}$ & $1.093^{* * *}$ \\
& $(.063)$ \\
\hline
\end{tabular}




\begin{tabular}{|c|c|}
\hline$\phi_{2}$ & $\begin{array}{l}-.086 \\
(.094)\end{array}$ \\
\hline \multirow[t]{2}{*}{$\phi_{3}$} & \\
\hline & $(.094)$ \\
\hline \multirow[t]{2}{*}{$\phi_{4}$} & .059 \\
\hline & $(.094)$ \\
\hline \multirow[t]{2}{*}{$\phi_{5}$} & .017 \\
\hline & $(.094)$ \\
\hline \multirow[t]{2}{*}{$\phi_{6}$} & -.152 \\
\hline & $(.094)$ \\
\hline \multirow[t]{2}{*}{$\phi_{7}$} & .145 \\
\hline & $(.094)$ \\
\hline \multirow[t]{2}{*}{$\phi_{8}$} & -.008 \\
\hline & $(.094)$ \\
\hline \multirow[t]{2}{*}{$\phi_{9}$} & .004 \\
\hline & $(.094)$ \\
\hline \multirow[t]{2}{*}{$\phi_{10}$} & -.053 \\
\hline & $(.093)$ \\
\hline \multirow[t]{2}{*}{$\phi_{11}$} & .150 \\
\hline & $(.093)$ \\
\hline \multirow[t]{2}{*}{$\phi_{12}$} & $-.135^{* *}$ \\
\hline & $(.062)$ \\
\hline$R^{2}$ & .968 \\
\hline$D-W$ & 1.984 \\
\hline SSR & .271 \\
\hline$F$ & 609.04 \\
\hline$R M S E$ & .0325 \\
\hline
\end{tabular}

Notes: See the previous tables.

\section{Summary}

This paper examines the predictive performance of several foreign exchange rate forecast models, namely, linear time-series, the vector autoregression model, and various time-series trends. For every such forecast model, we calculate its root mean square forecast error (RMSE) as

$$
\mathrm{RMSE}=\sqrt{\left(\sum_{\mathrm{t}=1}^{\mathrm{n}}\left(\mathrm{A}_{\mathrm{t}}-\mathrm{F}_{\mathrm{t}}\right)^{2}\right) / \mathrm{n}}
$$

Where $\mathrm{n}=$ the number of observations, $\mathrm{A}=$ the actual value of the dependent variable, and $\mathrm{F}=$ the forecast value. The forecast model with the smallest RMSE is the predictor chosen as part of exchange rate forecasting. Movements in exchange rates may result from either a parametric change in the above determinants or an artificial intervention by governments.

\section{References}

Agacer, G. M., Arize, A. C., Kasibhatla, M. K., Kallianiotis, I. N., \& Malindretos, J. N. (2015). Several Econometric Tests of Exchange Rate Efficiency for a Few European Countries. International Journal of Financial Research, 
6(4), 194-206. https://doi.org/10.5430/ijfr.v6n4p194

Alexander, S. (1952, April). Effects of a Devaluation on a Trade Balance. International Monetary Fund Staff Papers, (No. 2, pp.263-78). https://doi.org/10.2307/3866218

Arize, A. C., Berendt, C. J., Campanelli-Andreopoulos, G., Kallianiotis, I. N., \& Malindretos, J. N. (2016). Foreign Currency Forecasts: A Combination Analysis. NMIMS Journal of Economics and Public Policy, 1(2), 16-22. https://epp-journal.nmims.edu/2016/11/foreign-currency-forecasts-a-combination-analysis/

Arize, A. C., Berendt, C. J., Campanelli-Andreopoulos, G., Kallianiotis, I. N., \& Malindretos, J. N. (2017). Foreign Currency Prognostication: Diverse Tests for Germany. International Journal of Financial Research, 8(3). https://doi.org/10.5430/ijfr.v8n3p111

Arize, A. C., Berendt, C. J., Kallianiotis, I. N., Malindretos, J. N., \& Panayides, A. (2015). Prognostication Models Applied to the US Dollar and the Japanese Yen. The International Journal of Finance, 27(4).

Arize, A. C., Emmanuel, I., \& Malindretos, J. N. (2017). Do Exchange Rate Changes Improve the Trade Balance? An Assymmetric Nonlinear Cointegration Approach. International Review of Economics and Finance, 49, 313-326. https://doi.org/10.1016/j.iref.2017.02.007

Arize, A. C., Ioannis, N. K., Liu, S., Malindretos, J. N., \& Verrios, A. (2015). Statistical Specifications and Diverse Tests of Efficiency in European Foreign Exchange Markets. International Journal of Economics and Finance, 7(10), 235-246. https://doi.org/10.5539/ijef.v7n10p235

Arize, A. C., Kallianiotis, I. N., Kalu, E., Malindretos, J. N., \& Scoullis, M. (2017). A Multitude of Econometric Tests Forecasting the Dutch Guilder. International Journal of Economics and Finance, 9(9), 94-102. https://doi.org/10.5539/ijef.v9n9p94

Arize, A. C., Malindretos. J. N., \& Ghosh, D. (2015). Purchasing Power Parity-Symmetry and Proportionality: Evidence in 116 Countries. International Review of Economics and Finance, 37, 69-85. https://doi.org/10.1016/j.iref.2014.11.014

Atsalakis, G. S., \& Valavanis, K. P. (2009) Forecasting stock market short-term trends using a neuro-fuzzy based methodology. Expert Systems with Applications, 36(7), 10696-1070. https://doi.org/10.1016/j.eswa.2009.02.043

Atsalakis, G. S., \& Valavanis, K. P. (2009) Surveying stock market forecasting techniques - Part II: Soft computing methods. Expert Systems with Applications, 36(3), 5932-5941. https://doi.org/10.1016/j.eswa.2008.07.006

Branson, W. (1968). Financial Capital Flows in the U.S. Balance of Payments. Amsterdam, Netherlands: North Holland Publishing Co.

Cumby, R. F., \& Obstfeld, M. (1981). A Note on Exchange Rate Expectations and Nominal Interest Differentials: A Test of the Fisher Hypothesis. Journal of Finance, 6, 687-703. https://doi.org/10.1111/j.1540-6261.1981.tb00654.X

Dritsakis, N. (2004). Tourism as a Long-run Economic Growth Factor: An Empirical Investigation for Greece Using Causality Analysis. Tourism Economics, 10(3), 305-316. https://doi.org/10.5367/0000000041895094

Frenkel, J. A. (1976). A Monetary Approach to the Exchange Rate: Doctrinal Aspects and Empirical Evidence. Scandinavian Journal of Economics, 78(2), 200-24. https://doi.org/10.2307/3439924

Frenkel, J. A., \& Johnson, H. G. (1976). The Monetary Approach to the Balance of Payments. Toronto: University of Toronto Press.

Frenkel, J. A., \& Johnson, H. G. (Eds.) (1978). The Economics of Exchange Rates. Reading, MA: Addison-Wesley.

Frenkel, J. A., Gylfason, T., \& Helliwell, J. F. (1980, September). A Synthesis of Monetary and Keynesian Approaches to Short-Run Balance of Payments Theory. The Economic Journal, 90, 582-92. https://doi.org/10.2307/2231928

Grubel, H. G. (1965). Profits From Forward Exchange Speculation. Quarterly Journal of Economics, 79, $248-62$. https://doi.org/10.2307/1880630

International Monetary Fund. (1976-1982). International Financial Statistics. Washington, DC: International Monetary Fund.

Isard, P. (1978). Exchange Rate Determination: A Survey of Popular Views and Recent Models. Princeton Studies in International Finance (No. 42). Princeton, NJ: Princeton University Press. 
Kallianiotis, I. N. (1985). Exchange Rates and Rational Expectations. Unpublished doctoral dissertation, Graduate Center, City University of New York, New York, New York.

Kallianiotis, I. N. (1988). A Theoretical Monetary and Real Approach to the Balance of Payments. Greek Economic Review, 10(2), 383-404.

Kallianiotis, I. N., et al. (2000). The Traditional Approach to Balance of Payments Adjustment under Flexible Exchange Rates. In A. C. Arize, et al. (Eds.), Balance of Payments Adjustment: Macro Facets of International Finance Revisited (pp. 171-199). Westport, CT: Greenwood Publishing Group, Inc.

Kemp, D. S. (1975, April). A Monetary View of the Balance of Payments. St. Louis Federal Reserve Bank Review, 14-22.

Keynes, J. M. (1923). A Tract on Monetary Reform. London, UK: Macmillan.

Laffer, A. B., \& Miles, M. A. (1982). International Economics in an Integrated World. Glenview, IL: Scott Foresman. Leamer, E., \& Stern, R. M. (1970). Quantitative International Economics. Chicago, IL: Aldine Publishing Co.

Magee, S. P. (1976). The Empirical Evidence on the Monetary Approach to the Balance of Payments and Exchange Rates. The American Economic Review, 66(2), 163-70. Retrieved from https://www.jstor.org/stable/1817215

Malindretos, J. N. (1984). The Traditional and Monetary Approaches to the Balance of Payments: A Theoretical Comparison. American Business Review, 2(1), 31-47.

Malindretos, J. N. (1988). The Keynesian and the Monetary Approaches to International Finance: A Reexamination. The International Journal of Finance, 1(1), 46-89.

Malindretos, J. N. (1991). An Examination of the Two Views of International Finance for an Advanced, Medium-Sized Reserve Currency Country. Advances in Quantitative Analysis of Finance and Accounting, 1(B), 183-214.

Meade, J. E. (1951). The Theory of International Economic Policy Volume 1: The Balance of Payments. London, UK: Oxford University Press.

Mussa, M. (1976). The Exchange Rate, the Balance of Payments and Monetary and Fiscal Policy Under a Regime of Controlled Floating. Scandinavian Journal of Economics, 78(2), 229-35. https://doi.org/10.2307/3439926

Orphanides, A., \& van Norden, S. (2002). The Unreliability of Output-Gap Estimates in Real Time. Review of Economics and Statistics, 84(4), 569-583. https://10.1162/003465302760556422

Pindyck, R. S., \& Rubinfeld, D. L. (1981). Econometric Models and Economic Forecasts. New York, NY: McGraw-Hill.

Putnam, B. H., \& Wilford, D. S. (Eds.) (1978). The Monetary Approach to International Adjustment. New York, NY: Praeger.

Robinson, J. (1947). The Foreign Exchanges. In J. Robinson (Ed.), Essay in the Theory of Employment (Vol. IV, 2nd ed.). Oxford, UK: Blackwell.

Taylor, A. M. (2002). A Century of Purchasing-Power Parity. Review of Economics and Statistics, 84(1), 139-150. https://10.1162/003465302317331973

Taylor, M. P. (1995). The Economics of Exchange Rates. Journal of Economic Literature, 33(1), 13-47. Retrieved from http://www.jstor.org/stable/2728909 